\title{
Corrigendum
}

\section{Atlantic puffin diet reflects haddock and redfish abundance in the Gulf of Maine}

\section{Katelyn M. Depot*, Lauren C. Scopel, Stephen W. Kress, Paula Shannon, Antony W. Diamond, Kyle H. Elliott}

Mar Ecol Prog Ser 656: 75-87, 2020, https://doi.org/10.3354/meps13537

*Corresponding author: katelyn.depot@mail.mcgill.ca

- In Table 1 on page 81, the PC2 values for Haddock (SRP colonies) and Redfish (rows 4 and 6, respectively) in the column 'Prop. variance' were switched. The correct values for this column (from top to bottom), should be 0.613 , $0.306,0.852, \mathbf{0 . 1 0 6}, 0.705, \mathbf{0 . 2 7 4}$. The corrected Table is given below and in the online version of the article at https://www.int-res.com/articles/meps_oa/m656p075.pdf.

Table 1. PCA results for haddock and Acadian redfish proportions in Atlantic puffin diet across 4 colonies (see Fig. 1) between 2005 and 2017, showing the proportion of variation in use of each species explained by PC1 and PC2 and the loadings of each colony on each principal component. For haddock, PCA was performed both including and excluding MSI. Redfish were not observed on MSI

\begin{tabular}{|lcccccc|}
\hline \multirow{2}{*}{ Prey item } & \multirow{2}{*}{ PC } & Prop. & \multicolumn{5}{c|}{ Loadings } \\
\cline { 5 - 7 } & & variance & EER & MR & SINWR & MSI \\
\hline Haddock & 1 & 0.613 & 1.67 & 2.33 & 1.86 & 1.88 \\
(all colonies) & 2 & 0.306 & 0.726 & 0.457 & 1.16 & -2.35 \\
Haddock & 1 & 0.852 & 1.82 & 2.34 & 2.15 & \\
(SRP colonies) & 2 & 0.106 & 1.12 & -0.413 & -0.496 & \\
Redfish & 1 & 0.705 & 1.73 & 1.68 & 1.06 & \\
& 2 & 0.274 & 1.24 & -0.906 & -0.589 & \\
& & & & & & \\
\end{tabular}

